\title{
Revisión sistemática: Los corticoides intrarticulares son eficaces en la artrosis de rodilla
}

Corticosteroid injections for osteoarthritis of the knee: meta-analysis. Arrol B et al. BMJ;328:869-70.

\section{Objetivo}

Determinar si las inyecciones intrarticulares de corticoides son eficaces para mejorar los síntomas de la artrosis de rodilla.

\section{Fuentes de Datos}

Base de datos Cochrane, Medline (1966-2003), Embase (19802003).

\section{Selección de estudios y extracción de los datos}

Ensayos clínicos controlados y aleatorizados (ECCAs), que evaluaran mejoría sintomática (dolor y percepción subjetiva de mejoría) con corticoides intrarticulares (dosis variables) en artrosis de rodiIla. Se realizó un análisis pre-especificado de subgrupos para evaluar la calidad de los estudios, la dosis utilizada, la duración del efecto, la especialidad del médico que realizaba la inyección y el estado previo de la rodilla.Se encontraron 41 estudios de los cuales 10 cumplían los criterios de inclusión.

\section{Resultados principales}

Se obtuvo información de 6 estudios con seguimiento a dos semanas, con mejoría de los síntomas en los pacientes que recibieron corticoides (ver tabla).
Tabla 1: Mejoría sintomática con corticoides intrarticulares

\begin{tabular}{l|c|c|c|c} 
Resultados & $\begin{array}{c}\text { Grupo Tratamiento } \\
\text { N de } \\
\text { mejoria / N total }\end{array}$ & $\begin{array}{c}\text { Grupo Control } \\
\text { N de mejorí / } \\
\text { N total }\end{array}$ & $\begin{array}{c}\text { Riesgo Relativo } \\
\text { (IC95\%) }\end{array}$ & $\begin{array}{c}\text { Número } \\
\text { Necesario } \\
\text { a Tratar }\end{array}$ \\
\hline $\begin{array}{l}\text { Mejoría a la dos } \\
\text { semanas (6 ECCA) }\end{array}$ & $99 / 160$ & $70 / 157$ & $1.66(1.37-2.01)$ & $1.3-3.5$ \\
\hline $\begin{array}{l}\text { Mejoría a las 16-24 } \\
\text { semanas (2 EOCA } \\
\text { de alta calidad, a } \\
\begin{array}{l}\text { altas dosis de } \\
\text { corticoides) }\end{array}\end{array}$ & $28 / 63$ & $13 / 65$ & 2.09 (IC 1.2-3.65) & 4.4 \\
\hline
\end{tabular}

No se reportaron daños de importancia. Un estudio investigó la pérdida potencial de espacio articular y no encontró diferencias a los dos años de seguimiento.De los dos estudios de alta calidad que evaluaron la mejoría a las 16-24 semanas, individualmente no mostraron mejoría significativa. Sin embargo, al ser analizados en conjunto, sí la presentaron, y el doble de pacientes mejoraron en el grupo corticoides en relación al grupo control (ver tabla).

\section{Conclusiones}

Existe evidencia sobre la eficacia del tratamiento intrarticular con corticoides para mejorar los síntomas de la artrosis de rodilla a corto plazo (hasta 2 semanas) y a mediano plazo (16-24 semanas). Una dosis equivalente a $50 \mathrm{mg}$ de prednisona sería necesaria para obtener beneficios entre las 16-24 semanas.La inyección de corticoides asociada al lavaje articular requiere mayor investigación. Actualmente no hay evidencia de que este tipo de tratamiento promueva la progresión de la enfermedad. Las inyecciones repetidas (cada 3 meses y a dosis altas) parecen seguras dentro de los dos años pero esto requiere confirmación por otros estudios.

\section{Comentario}

La artrosis de rodilla es una entidad muy prevalente en atención primaria, sobre todo en mayores de 55 años, y es la principal causa de incapacidad en adultos mayores ${ }^{1}$. No existe tratamiento curativo para esta entidad (excepto el reemplazo de la articulación) por lo que el tratamiento se dirige a la reducción del dolor y el mantenimiento o mejoramiento de la función. En este sentido, la infiltración de la rodilla con corticoides es un tratamiento habitual que ha dado lugar a algunas controversias: por un lado, los trabajos científicos sugerían un beneficio poco extendido en el tiempo, mientras que los médicos veían en sus consultorios respuestas más sostenidas, quizás debido a que los estudios usaban dosis menores que las recomendadas por las asociaciones de expertos y porque las escalas de dolor podrían ser un punto final a medir poco sensible.Por otro lado, se ha propuesto que este tipo de inyecciones podría promover la destrucción del cartílago y la atrofia tisular. El dato más significativo que aporta este meta-análisis es la evidencia acerca de la persistencia del beneficio clínico del tratamiento a las 16-24 semanas, dato a favor de la eficacia de los corticoides sostenida en el tiempo. Por otro lado, los números necesarios para tratar son clínicamente significativos (NNT 4,4). Si bien la dosis de corticoides necesaria para obtener estos resultados no queda clara en esta revisión, una dosis de $25 \mathrm{mg}$ de prednisona parece eficaz para el control del dolor dentro de las dos semanas, y los dos estudios a altas dosis (equivalentes a 50 $\mathrm{mg}$ de prednisona) mostraron resultados estadísticamente significativos sotenidos hasta 24 semanas. Esto sugieree que dosis más altas producirían un beneficio más prolongado. En los estu- dios con seguimiento de hasta 24 semanas no se reportaron eventos adversos importantes, y el único estudio que los evaluó a los 2 años tampoco reportó daños importantes. Es de destacar que los datos que se conocen sobre el hipotético daño en el cartílago por los corticoides surgen de una experiencia hecha en rodillas sanas de perros en las que infiltraron varias veces en un corto período (de allí surge el concepto de que no deben hacerse más de 3 por año en la misma articulación). Sin embargo, en el cartílago afectado por artrosis el efecto sería beneficioso porque los corticoides interferirían con un mecanismo inflamatorio que lo destruye, permitiendo así el inicio de la rehabilitación muscular del cuádriceps, lo cual es vital para la rodilla.Como puntos cuestionables de este trabajo, las características clínicas de las poblaciones tratadas no fueron reportadas y los estudios seleccionados son pequeños, por lo que efectos adversos raros como la artritis séptica (que se estima en 1 de cada 200.000 infiltraciones) no pueden ser evaluados.Tampoco queda muy claro en qué subgrupo de pacientes sería más efectivo el tratamiento.

Conclusiones del comentador: Los resultados de este metaanálisis permiten afirmar que dosis equivalentes a $50 \mathrm{mg}$ de prednisona intrarticulares parecen eficaces para disminuir la gonalgia relacionada a la artrosis, y el efecto beneficioso se mantiene hasta 24 semanas luego de la infiltración. Se necesitan estudios a largo plazo que evalúen la seguridad de las inyecciones repetidas, aunque debemos recordar que el hipotético daño que éstas provocarían tampoco está sustentado por evidencia contundente.

\section{Dr. Gabriel Kñallevsky [ Unidad de Medicina Familiar y Preventiva. Hospital Italiano de Buenos Aires ]}

